\title{
A ROBUST APPROACH FOR ACOUSTIC NOISE SUPPRESSION IN SPEECH USING ANFIS
}

\author{
Radek Martinek - Michal Kelnar - Jan Vanus \\ Petr Bilik - Jan Zidek
}

\begin{abstract}
The authors of this article deals with the implementation of a combination of techniques of the fuzzy system and artificial intelligence in the application area of non-linear noise and interference suppression. This structure used is called an Adaptive Neuro Fuzzy Inference System (ANFIS). This system finds practical use mainly in audio telephone (mobile) communication in a noisy environment (transport, production halls, sports matches, etc). Experimental methods based on the two-input adaptive noise cancellation concept was clearly outlined. Within the experiments carried out, the authors created, based on the ANFIS structure, a comprehensive system for adaptive suppression of unwanted background interference that occurs in audio communication and degrades the audio signal. The system designed has been tested on real voice signals. This article presents the investigation and comparison amongst three distinct approaches to noise cancellation in speech; they are LMS (least mean squares) and RLS (recursive least squares) adaptive filtering and ANFIS. A careful review of literatures indicated the importance of non-linear adaptive algorithms over linear ones in noise cancellation. It was concluded that the ANFIS approach had the overall best performance as it efficiently cancelled noise even in highly noise-degraded speech. Results were drawn from the successful experimentation, subjective-based tests were used to analyse their comparative performance while objective tests were used to validate them. Implementation of algorithms was experimentally carried out in Matlab to justify the claims and determine their relative performances.
\end{abstract}

K e y w o r d s: adaptive neuro fuzzy inference system, background noise, colored noise, noise cancellation, voice communication

\section{INTRODUCTION}

Audio communication [22] through modern communication interfaces (PSTN, IP phones, mobile communications, satellite phones, radios, etc) is an integral part of human lives in today's over-technologized world. In real conditions, audio communication is often degraded by the noise in the background [12]. Such a noise can be, for example, a noise from motor vehicle engines, a noise from machines in production halls, city sounds (traffic, etc), a noise at sports and social events, etc.

The authors of the article base their work on the results of their own studies published in $[1,2]$. The work in this article builds on these studies and extends them. In these studies, the authors address the issue of removing the disturbing components from useful signals (noise suppression during audio communication in the cockpit of a fighter airplane [1], noise suppression in foetal ECG $[2,32,38])$ using linear adaptive filtration [5]. Linear adaptive filters play an important role in statistical signal processing [6]. Currently, in commercial applications for suppressing noise during audio communication, the most widespread algorithm is the LMS adaptive one [6]. The LMS algorithm is mathematically simple and undemanding [29]. In real applications, however, it achieves a lower convergence rate $[6]$ and a higher error of the filtration process [6]. Better results are achieved using the RLS family of algorithms $[6,35]$ (an extremely low error rate and extremely high speed of convergence). The results of the experiments carried out by the authors $[1,2]$ show that the basic RLS algorithm [18] is mathematically very demanding in terms of actual implementation [18]. Many studies $[8,13,19]$ further indicate that we encounter the nonlinear nature of disturbance $[4,13,21]$, which cannot be completely eliminated using a linear filter $[1,4]$. Due to the reasons discussed above, the authors focus on the use of a neuro-fuzzy system $[19,20]$. A number of studies suggest $[8,9,17]$ that such a system could achieve better results than commercially used systems.

\section{THE ADAPTIVE NEURO-FUZZY INFERENCE SYSTEM}

ANFIS is an adaptive feed forward neural network that is functionally equivalent to a fuzzy inference system of the Sugeno type (Takagi-Sugeno) [19, 28, 32, 34, 36-38].

A Two Rule Sugeno ANFIS has rules of the form [19]

$$
\begin{aligned}
& \text { IF } x \text { is } A_{1} \text { and } y \text { is } B_{1} \text {, THEN } f_{1}=p_{1} x+q_{1} y+r_{1} . \\
& \text { IF } x \text { is } A_{2} \text { and } y \text { is } B_{2} \text {, THEN } f_{2}=p_{2} x+q_{2} y+r_{2} .
\end{aligned}
$$

Where $x$ and $y$ are the inputs, $A_{i}$ and $B_{i}$ are the fuzzy sets, $f_{i}, i=1,2$ are the output fuzzy system, and $p_{i}, q_{i}$

* Department of Cybernetics and Biomedical Engineering, VSB - Technical University of Ostrava, 17. listopadu 15/2172, 708 33 Ostrava, Czech Republic, \{radek.martinek, michal.kelnar, jan.vanus, jan.zidek, petr.bilik\}@vsb.cz 


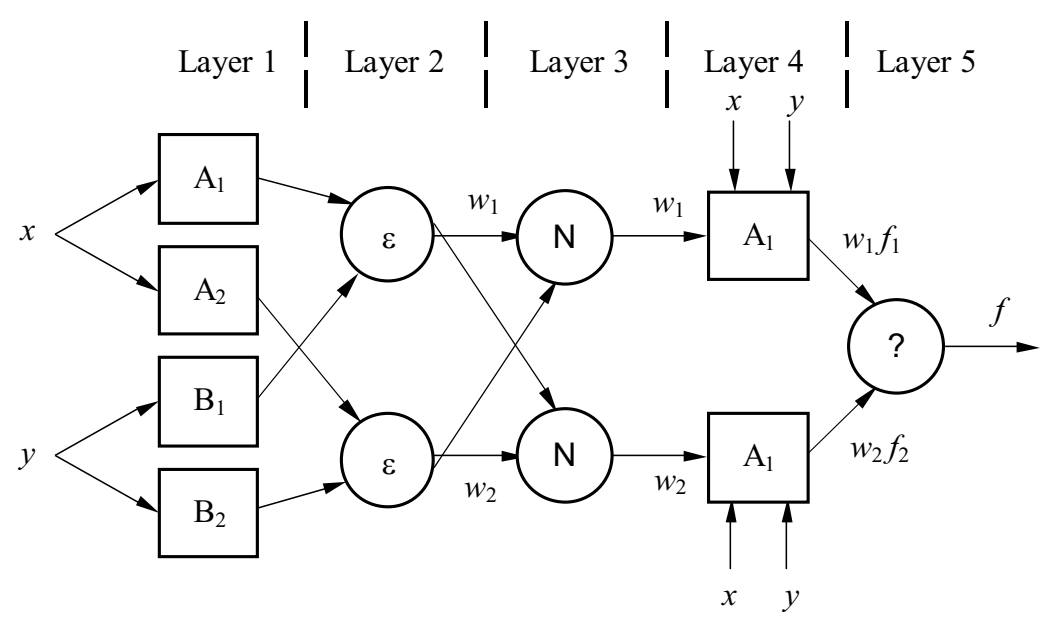

Fig. 1. The architecture of ANFIS

and $r_{i}$ are the design parameters which are determined during the training process [19].

The ANFIS architecture to implement these two rules is shown in Fig. $1[19,28]$ in which a circle indicates a fixed node whereas a square indicates an adaptive node. As figure illustrates, ANFIS architecture consists of five layers [19]. The functioning of the ANFIS is described as $[19,28,34]$ :

\section{Layer 1}

The output of each node is

$$
\begin{aligned}
& O_{1, i}=\mu_{A_{i}}(x) \text { for } i=1,2 . \\
& O_{1, i}=\mu_{B_{i-2}}(y) \text { for } i=3,4 .
\end{aligned}
$$

Where $x$ and $y$ are the inputs to node $i, A$ is a linguistic label and $\mu_{A_{i}}(x)$ and $\mu_{B_{i-2}}(y)$ can adopt any fuzzy membership function. So, the $O_{1, i}$ is essentially the membership grade for $x$ and $y$. The membership functions could be anything but for illustration purposes we will use the bell shaped function given by

$$
\mu_{A_{1}}(x)=\frac{1}{1+\left|\left(x-c_{i}\right) / a_{i}\right|^{2 b_{i}}} .
$$

Where $\left\{a_{i}, b_{i}, c_{i}\right\}$ is the parameter set which changes the shapes of the MF degree with maximum value equal to 1 and minimum equal to 0 .

\section{Layer 2}

Every node in this layer is a fixed node labelled $\Pi$, whose output is the product of all incoming signals

$$
O_{2, i}=w_{i}=\mu_{A_{i}}(x) \mu_{B_{i}}(y), \quad i=1,2 .
$$

\section{Layer 3}

The $i$-th node of this layer, labelled $N$, calculates the normalized firing strength as

$$
O_{3, i}=\bar{w}_{i}=\frac{w_{i}}{w_{1}+w_{2}}, \quad i=1,2 .
$$

\section{Layer 4}

Every node $i$ in this layer is an adaptive node with a node function

$$
O_{4, i}=\bar{w}_{i} f_{i}=\bar{w}_{i}\left(p_{i} x+q_{i} y+r_{i}\right) .
$$

Where $\bar{w}_{i}$ is the output of layer 3 . The parameters in this layer $\left(p_{i}, q_{i}, r_{i}\right)$ are to be determined and are referred to as the consequent parameters.

\section{Layer 5}

The single node in this layer is a fixed node labelled $\Sigma$, which computes the overall output as the summation of all incoming signals:

$$
\text { Overall output }=O_{5, i}=\sum_{i} \bar{w}_{i} f_{i}=\frac{\sum_{i} w_{i} f_{i}}{\sum_{i} w_{i}} .
$$

\section{SUPPRESSING BACKGROUND NOISE DURING AUDIO COMMUNICATION IN A NOISY ENVIRONMENT}

Figure 2 shows a schematic diagram of the measurement workplace where the experiments were conducted. The experimental system includes two signal sources: the Speech Source and the Noise Source. These sources allow working with any signals in the wav format. Using G.R.A.S. 40PP CPP Free-field QA microphones as reference and primary MIC and NI DAQ 9234.

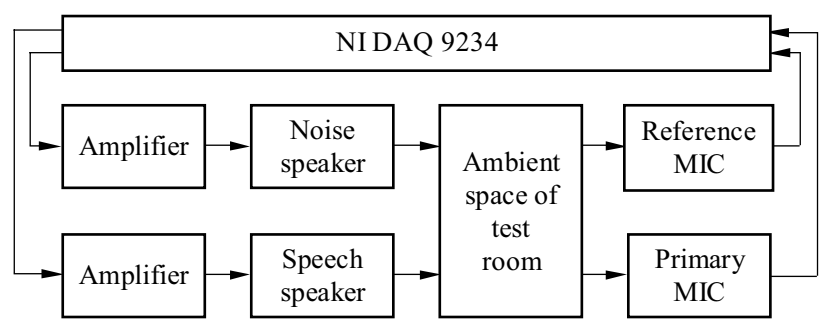

Fig. 2. Experimental measuring workplace 


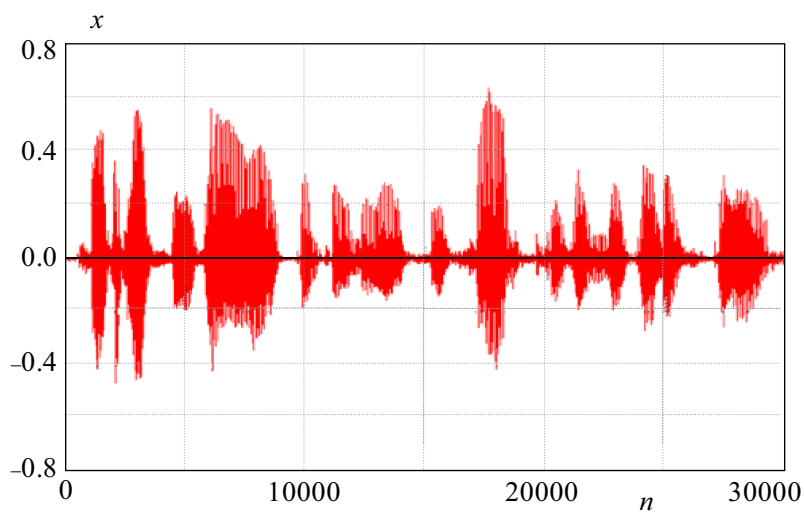

Fig. 3. Source signal $x[n]$ — original speech signal

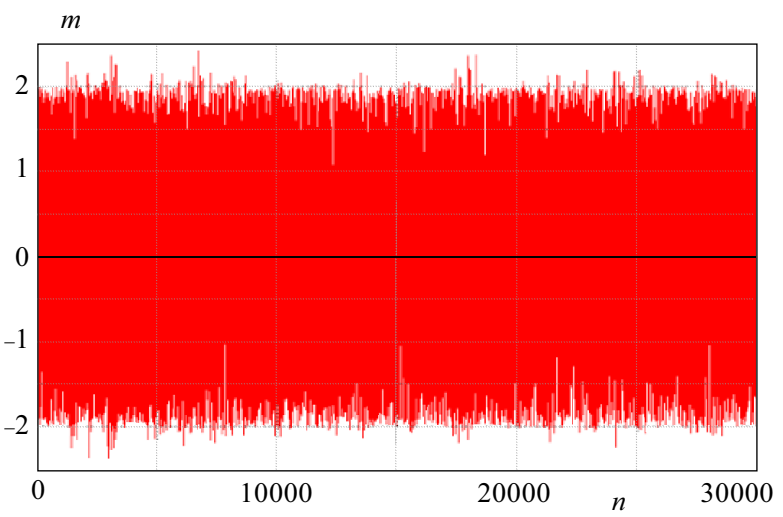

Fig. 5. Signal recorded by the primary microphone - signal measured $-m[n]$

The first source signal is the human voice $x[n]$, see Fig. 3. For the purposes of the experiments carried out, a test voice according to ITU-T P. 501 [10] was used (Test signals for the use in telephonometry).

In the experiments performed, the first $n=30000$ samples of audio recordings were used. The second source signal is noise $n_{1}[n]$. In the experiments conducted, a recorded engine noise was used. These source signals were reproduced by means of reference and primary loudspeakers, see Fig. 2.

The system designed has two entry points (a primary microphone and reference one). The first entry is a reference microphone that registers unwanted noise and this signal is denoted $n_{1}[n]$, see Fig. 4 (records only noise). The second input is a primary microphone (signal measured) that picks up the useful signal (voice) plus unwanted background noise, this signal is denoted $m[n]$, see Fig. 5.

Recording parameters: sampling frequency of $8 \mathrm{kHz}$, PCM audio format, bit rate $128 \mathrm{kbps}, 1$ channel mono), used standard microphone (omnidirectional).

The aim of the authors was to create a system that would reduce unwanted background noise $n_{1}[n]$ that contaminates the useful speech signal $x[n]$. The human voice used reaches values of $30 \mathrm{~dB}$ to $40 \mathrm{~dB}$ while the engine noise used reaches the value of about $80 \mathrm{~dB}$ to $100 \mathrm{~dB}$.

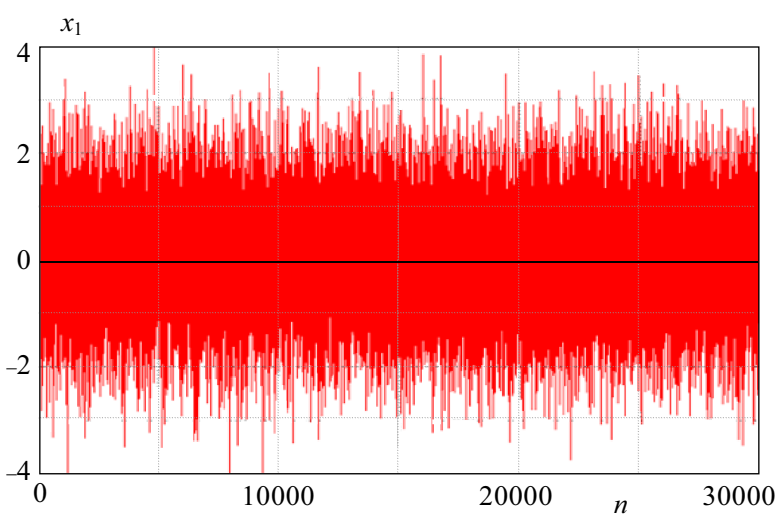

Fig. 4. Noise signal $n_{1}[n]$

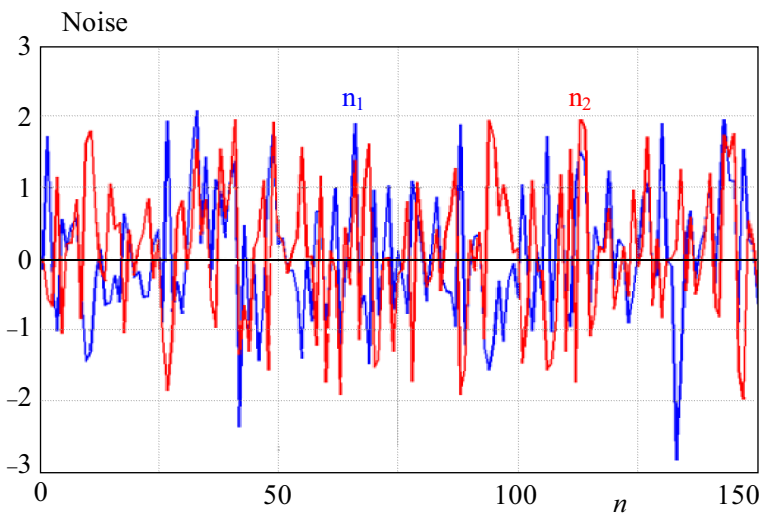

Fig. 6. Noise difference $\left(n_{1}\right.$ and $n_{2}$ - detail)

Therefore, it is evident that the clarity of radio communication in such a noisy environment would be very bad. As shown in Fig. 2, the easiest way how to suppress the unwanted background noise would be direct subtraction of the signal from the reference microphone $n_{1}[n]$ from the signal captured by the primary microphone $m[n]$. However, this approach will not work since the noise $n_{1}[n]$ picked up by the reference microphone is not the same as the noise that contaminates the voice signal $m[n]$ captured by the primary microphone, see Figs. 6 and $7\left(n_{1}[n] \rightarrow\right.$ Non-Linear Unknown System $\left.(N L U S) \rightarrow n_{2}[n]\right)$. Unfamiliar environment properties apply here (signal distortion due to the environment interference [5], delay [7], etc).

Another possible way was the use of a linear filter (frequency selective filters) [5]. However, these conventional filtration techniques cannot be used because of the spectrum time variability of the interfering and useful signals $[5,7]$.

If we considered the unknown environment (system) as linear, we could apply any adaptive algorithm [6] that will teach the FIR filter [18] to recognize the characteristics of the channel. If we then applied this filter to the signal from the reference microphone, which contains the unwanted background noise, we could subtract this unwanted noise successfully. Many studies [8,9,13], how- 


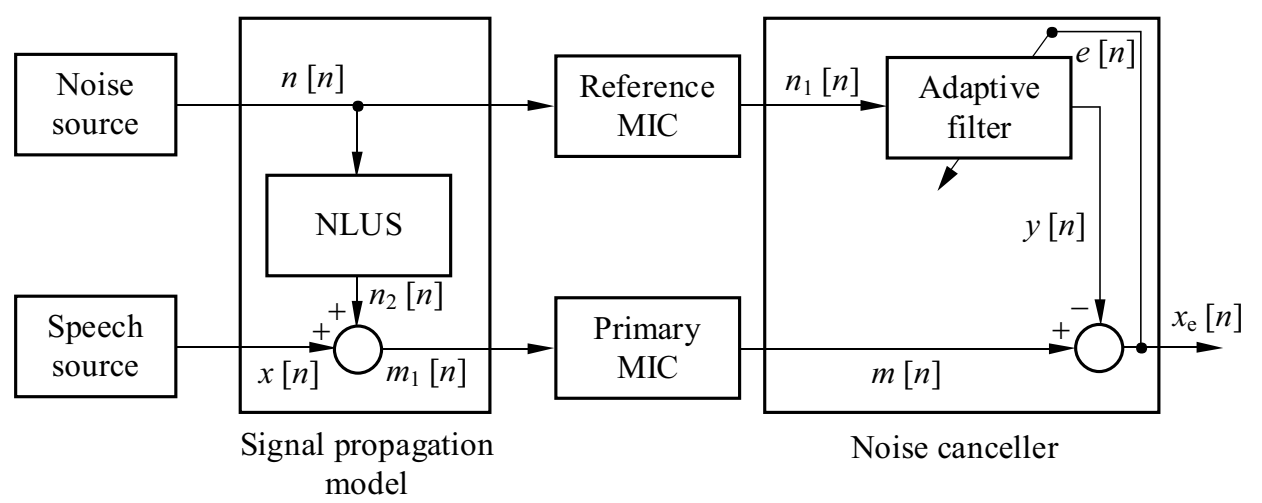

Fig. 7. Signal recorded by the primary microphone - signal measured $-m[n]$

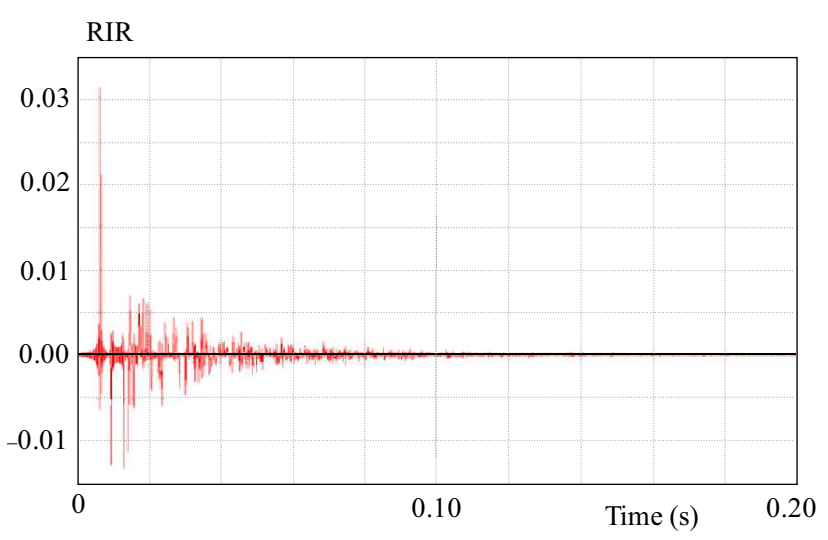

Fig. 8. The impulse response experimental room - RIR

ever, indicate that the real environment in a number of applications shows a nonlinear nature [4]. Then, the linear adaptive filtration techniques do not have satisfactory results here (in particular the LMS algorithm families [18]). The authors deal with the study of linear adaptive filters, type LMS and RLS, [8] in the publication [1,2] use this publication as a foundation.

\section{IMPLEMENTATION OF ANFIS INTO THE SYSTEM OF ADAPTIVE SUPPRESSION OF UNWANTED INTERFERENCE}

Figure 7 shows a principal diagram of the designed adaptive system on which the experiments were conducted.

The experiments were performed in a standard office room, whose parameters are defined in Fig. 7 (Details of the selected environment). Figure 8 shows the impulse response [23] of the experimental room. This response was determined on the basis of ITU-T - P34 [11].

In Fig. 7 signal $n_{2}[n]$ can be seen (coloured noise), this signal represents noise $n_{1}[n]$ after running through an unknown environment (interference, delay). Signal $m[n]$ is then given by the relation.

$$
m[n]=x[n]+n_{2}[n] .
$$

Where $m[n]$ is polluted by noise. In practice, $x[n]$ and $n_{2}[n]$ are not correlated [8], $x[n]$ is estimated from the polluted signal $m[n]$. Obviously, it is suitable that $n_{2}[n]$ is estimated. $n_{2}[n]$ is the delay and deformation of $n_{1}[n]$, $n_{2}[n]$ is nonmeasurable, as follows

$$
n_{2}[n]=f\left(n_{1}[n], n_{1}[n-1], n_{1}[n-2], \cdots\right) .
$$

Where function $f$ is unknown and nonlinear, its frequency range is usually overlapped with the frequency range of $m[n]$, so a frequency filter cannot be realized. Here, we use the ability of ANFIS network, which can approach the nonlinear function, letting ANFIS approach the colored $n_{2}[n]$ so estimated_x $[n]$ can be estimated [8]. When the ANFIS network approaches colored noise, the input is noise $n_{1}[n]$ and $n_{1}[n-1]$, and the membership function of every variable is a Gaussian function; the output sample should be colored noise, but it can not be obtained directly in practice. Here, it can be replaced with a measurable signal

$$
m[n]=x[n]+f\left(n_{1}[n], n_{1}[n-1], \cdots\right) .
$$

The output of the ANFIS can be the estimated value $y[n]$, the objective of the training ANFIS is to make the following error minimum

$$
\begin{array}{r}
e^{2}[n]=\|m[n]-y[n]\|^{2}=\left\|x[n]+n_{2}[n]-y[n]\right\|^{2}= \\
\left\|x[n]+n_{2}[n]-\hat{f}\left(n_{1}[n], n_{1}[n-1], n_{1}[n 2], \cdots\right)\right\|^{2}
\end{array}
$$

Where $\hat{f}$ is the nonlinear approach produced by the ANFIS network.

The above equation can be expanded, so we can get

$$
\begin{aligned}
& e^{2}[n]=\|x[n]\|^{2}+\left\|n_{2}[n]-y[n]\right\|^{2}= \\
& \quad\left\|x[n]+n_{2}[n]-\hat{f}\left(n_{1}[n], n_{1}[n-1], n_{1}\left[n_{2}\right], \cdots\right)\right\|^{2}
\end{aligned}
$$

Mathematical expectation is calculated in the equation. Note the expectation of $x[n]$ is zero (the condition suits for many problems or simple transform). $x[n]$ and 


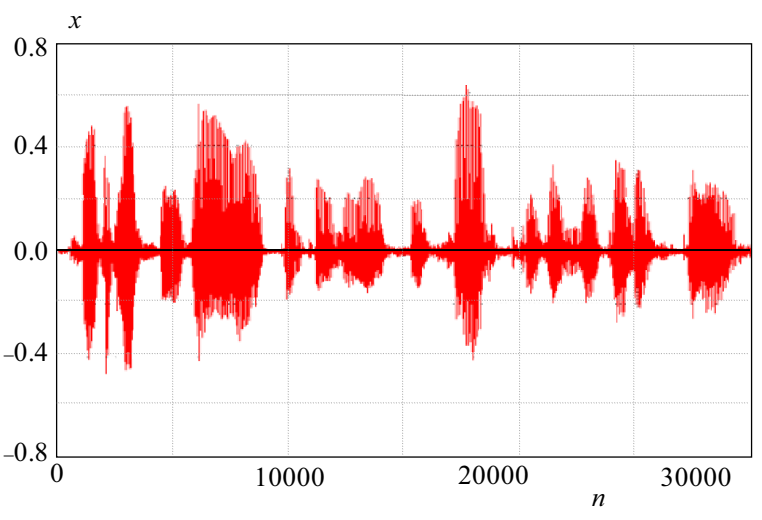

Fig. 9. Original speech signal

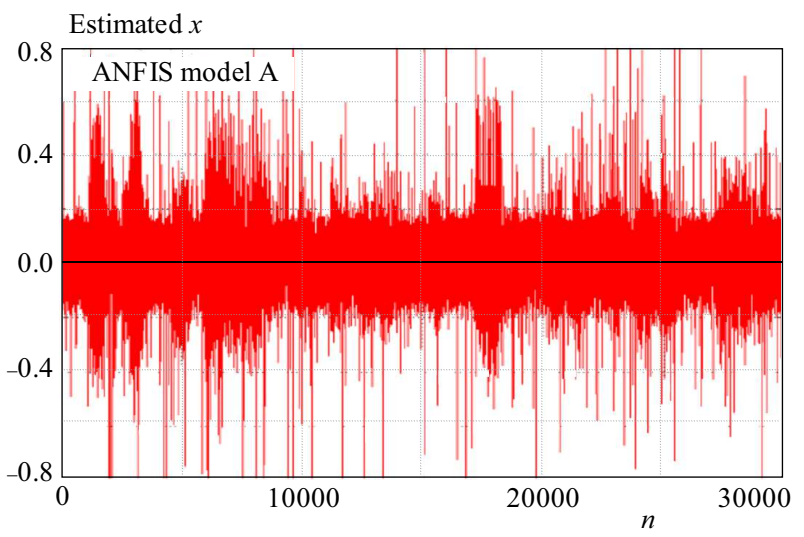

Fig. 11. Results of noise cancellation - ANFIS model A

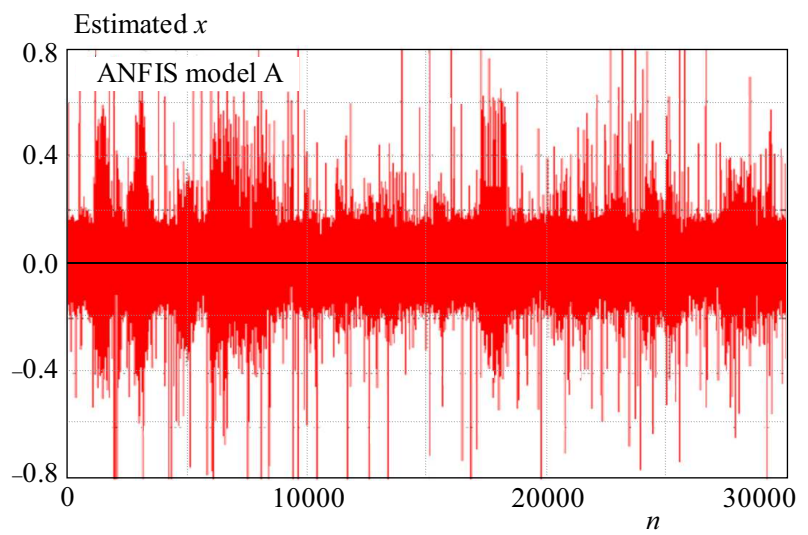

Fig. 13. Results of noise cancellation — ANFIS model C

$n_{1}[n]$ is noncorrelation, so $n_{2}[n], y[n]$ is noncorrelation, so

$$
E^{2}\left[e^{2}\right]=E\left(x^{2}\right)+E\left[\left(n_{2}-y\right)^{2}\right] .
$$

Makes $E\left(e^{2}\right)$ minimum, which is equivalent to $E\left[\left(n_{2}-\right.\right.$ $\left.y)^{2}\right]$ minimum, that is, make $y[n]$ approach $n_{2}[n]$ as much as possible in other words, function $\hat{f}$ produced by ANFIS will approach the practical noise transmission function with minimum mean square error.

In ideal conditions, $y[n]=n_{2}[n]$ so estimated_x $[n]=$ $x[n]$. ANFIS adjusts its parameter automatically and makes $n_{1}[n]$ process into $n_{2}[n]$, and minus $n_{2}[n]$ in

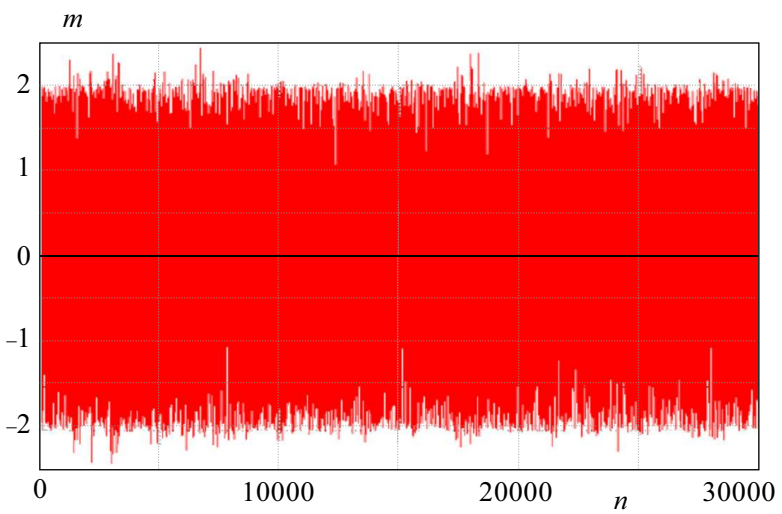

Fig. 10. Noisy speech signal

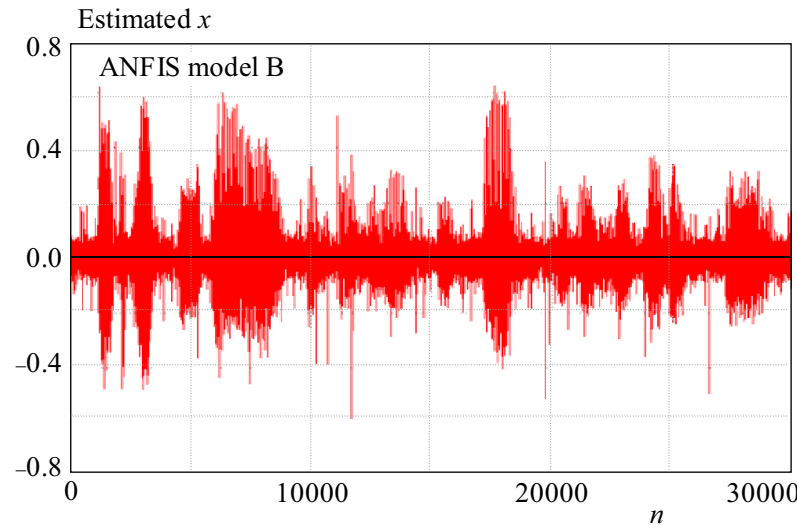

Fig. 12. Results of noise cancellation - ANFIS model B

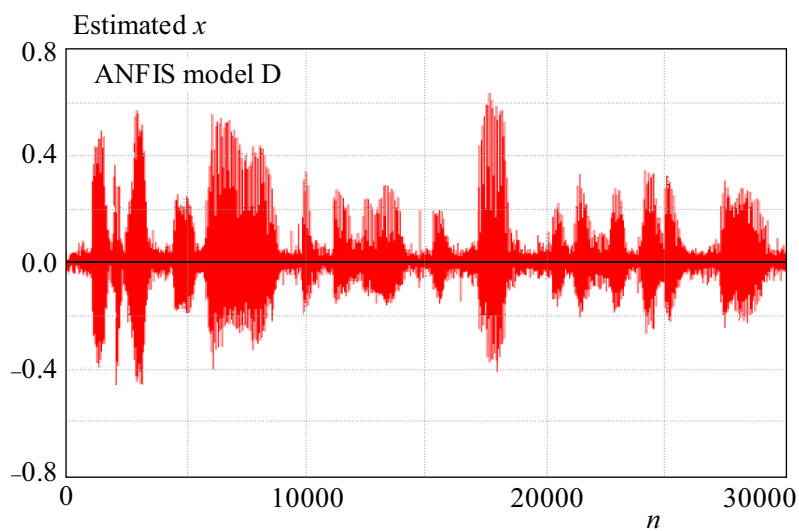

Fig. 14. Results of noise cancellation — ANFIS model D

the original input signal $m[n]$. Thus, the output signal estimated_x $[n]$ equals the useful signal $x[n]$ because of complete cancellation of the noise.

\section{THE RESULTS OF THE EXPERIMENTS CONDUCTED}

Various ANFIS networks (structures) were investigated in the experiments performed. An overview of the network models used is provided in Table 1. 
ANFIS functions were used for building of the ANFIS model [13] as well as for training (estimating) of the EVALFIS function [13]. A detailed description of work with ANFIS and EVALFIS functions in MATLAB environment can be found in $[14,15]$. Figures 9 to 23 show the results of experiments conducted. Figures 9 to 14 compare the time flows of the analysed signals.

Table 1. Information about anfis structures used

\begin{tabular}{|c|c|c|c|c|}
\hline \multicolumn{5}{|l|}{ ANFIS info } \\
\hline Building the ANFIS Model & $\mathrm{A}$ & $\mathrm{B}$ & $\mathrm{C}$ & $\mathrm{D}$ \\
\hline Number of nodes & 21 & 35 & 53 & 75 \\
\hline Number of linear parameters & 12 & 27 & 48 & 75 \\
\hline Number of nonlinear parameters & 12 & 18 & 24 & 30 \\
\hline Total number of parameters & 24 & 45 & 72 & 105 \\
\hline Number of fuzzy rules & 4 & 9 & 16 & 25 \\
\hline
\end{tabular}

Table 2. Resulting values of the SNR

\begin{tabular}{cccc}
\hline \multicolumn{4}{c}{ Improvement of the SNR Value } \\
\hline Building the & SNRin & SNRout & $\begin{array}{c}\text { SNR Improvement } \\
(\mathrm{dB})\end{array}$ \\
ANFIS Model & $(\mathrm{dB})$ & $(\mathrm{dB})$ & 22.3427 \\
\hline ANFIS Model A & -21.4765 & -0.8662 & 27.3837 \\
ANFIS Model B & -21.4961 & 5.8876 & 29.4705 \\
ANFIS Model C & -21.6184 & 7.8521 & 32.3423 \\
ANFIS Model D & -21.3832 & 10.9591 & 11.6858 \\
LMS [1,2] & -21.3832 & -9.6974 & 17.0191 \\
RLS [1,2] & -21.3832 & 4.3641 &
\end{tabular}

Table 3. Resulting values of the SSNR and DTW

\begin{tabular}{ccc}
\hline $\begin{array}{c}\text { Building the } \\
\text { ANFIS Model }\end{array}$ & $\begin{array}{c}\text { SSNR (dB) } \\
\text { improvement }\end{array}$ & $\begin{array}{c}\mathrm{d} \\
\text { (DTW distance) }\end{array}$ \\
\hline ANFIS Model A & 15.551 & 0.725 \\
ANFIS Model B & 16.754 & 0.630 \\
ANFIS Model C & 18.598 & 0.617 \\
ANFIS Model D & 19.689 & 0.692 \\
LMS [1,2] & 7.314 & 0.891 \\
RLS [1,2] & 9.749 & 0.797 \\
\hline
\end{tabular}

Table 2 shows the ability of the analysed ANFIS models to improve the value of SNR (Signal to Noise Ratio [26]). In the experiments performed, the SNR value of the contaminated speech signal and the signal after passing the system designed was determined. The difference between these values showed what improvement was achieved by each model. The SNR ratio is defined by the following relation $[26]$

$$
S N R=10 \log \frac{P_{s}}{P_{n}}[\mathrm{~dB}]
$$

where the values $P_{s}$ and $P_{n}$ indicate the power of the signal ( $s$ is signal) and noise ( $n$ bis noise).

If the $S N R=0 \mathrm{~dB}$, it means that both the signal and the noise have the same output. When $S N R>0$, the signal output is bigger than the noise output. When $S N R<0$, the reverse is true.
If we look at the acquired values stated in Table 2 , we can see that in the signal of the mixture of the speech signal and the noise SNR, the noise has a much greater output then the speech signal. If we evaluate the results of filtration by means of the tested ANFIS structures, it is clear that all the structures achieved a significant improvement in the SNR values.

Table 3 shows the ability of the analysed ANFIS models to improve the value of SSNR (segmental signal to noise ratio) [30]. In the experiments performed, the SSNR value of the contaminated speech signal and the signal after passing the system designed was determined. The difference between these values showed what improvement was achieved by each model. The SSNR ratio is defined by the following relation $[30,33]$

$$
S S N R=\frac{1}{K} \sum_{i=0}^{L-1} \underbrace{\left(10 \log \frac{\sum_{n=0}^{M-1} x_{i}^{2}(n)}{\sum_{n=0}^{M-1} n_{i}^{2}(n)}\right)}_{S N R_{i}} \cdot V A D_{i}
$$

Where $L$ is the number of segments of speech signal, $K$ is the number of segments in speech activity, $V A D_{i}$ is information about speech activity (values 0 and 1 ), further $x_{i}(n)=x(m i+n), n_{i}(n)=n(m i+n)$ - segments of length $M$ selected step $m$. More information in [3033 .

The DTW (Dynamic Time Warping) criterion in Tab. 3 is used to compare the similarity of two sequences of the speech signal to calculate the distance $d$ between them $[30,31,39]$ :

- reference sequence (original speech signal)

$$
x=\left(x_{1}, x_{2}, \ldots, x_{N}\right), \quad N \in \mathbb{N},
$$

- test sequence (output speech signal from ANFIS)

$$
y=\left(y_{1}, y_{2}, \ldots, y_{M}\right), \quad M \in \mathbb{N} .
$$

Evaluating the local distance for each pair of elements of these time-series using Manhattan distance (ie absolute value of difference), obtains the local cost matrix

$$
C \in \mathbb{R}^{N \times M}
$$

Where elements of cost matrix are

$$
C_{I, j}=\left|x_{i}-y_{j}\right|, i \in\{1,2, \ldots, N\}, j \in\{1,2, \ldots, M\}
$$

A path which runs through the low-cost areas of cost matrix is called warping path, defined as sequence

$P=\left(p_{1}, p_{2}, \ldots, L\right), \quad L \in \mathbb{N}$,
$p_{\ell}=\left(n_{\ell}, m_{\ell}\right) \in\{1, \ldots, N\} \times\{1, \ldots, M\}, \ell \in\{1,2, \ldots, L\}$.

satisfying the following conditions

i Boundary condition: $p_{1}(1,1) \wedge p_{L}=(N, M)$. 


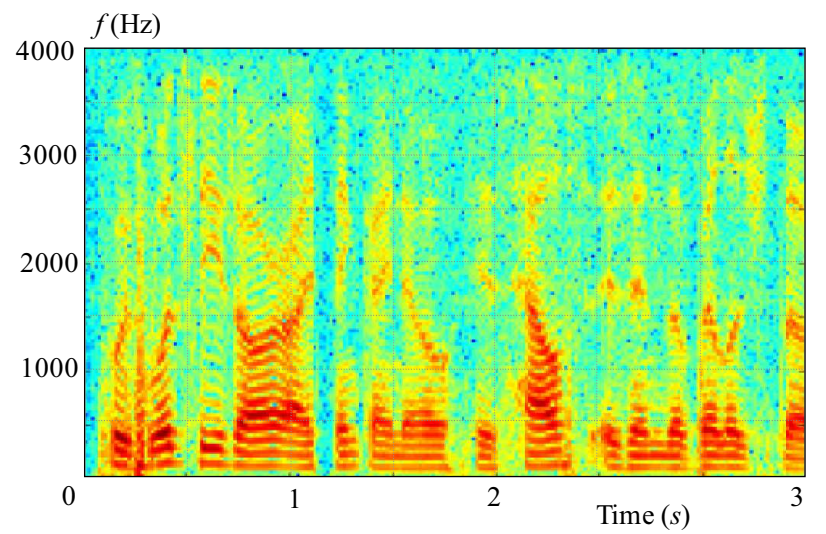

Fig. 15. Original speech signal

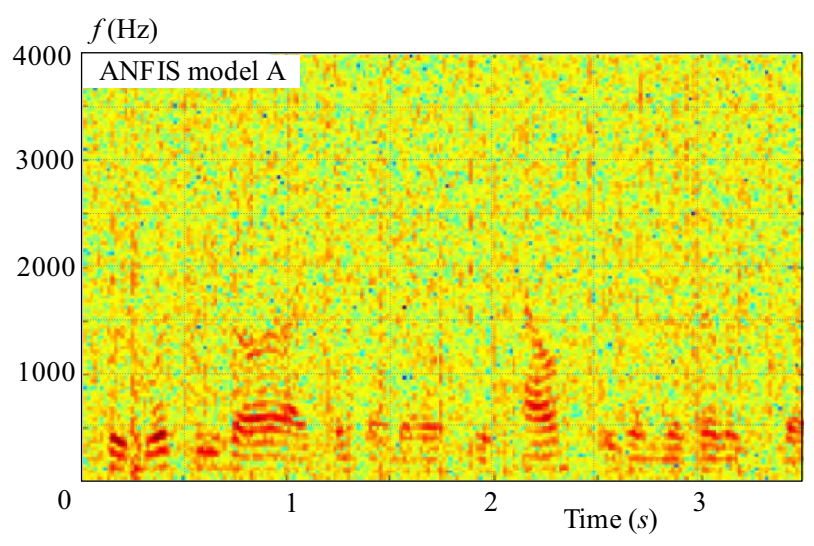

Fig. 17. Results of noise cancellation — ANFIS model A

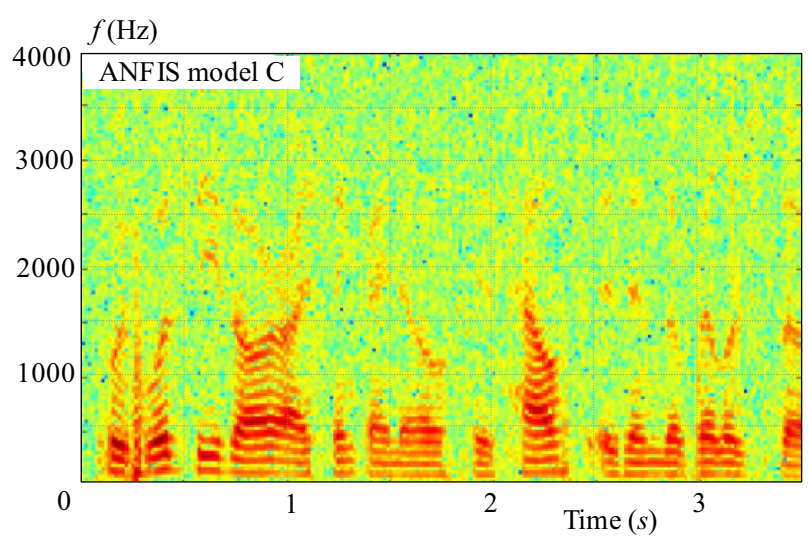

Fig. 19. Results of noise cancellation - ANFIS model C

ii Monotonicity condition: $n_{1} \leq n_{2} \leq \cdots \leq n_{L} \wedge$ $m_{1} \leq m_{2} \leq \cdots \leq m_{L}$

iii Step size condition: $p_{\ell+1}-p_{\ell} \in\{(1,0),(01),(1,1)\}$, $\ell \in\{1,2, \ldots, L-1\}$.

The optimal path is selected from the set of all available warping paths by distance function

$$
d=\min \left\{\Sigma_{l=1}^{L} p_{l}, p \in P^{N \times M}\right\} .
$$

Where $P^{N \times M}$ is the set of all possible warping paths for cost matrix $C$.

If we evaluate the results of filtration by means of the tested ANFIS structures, it is clear that all the structures

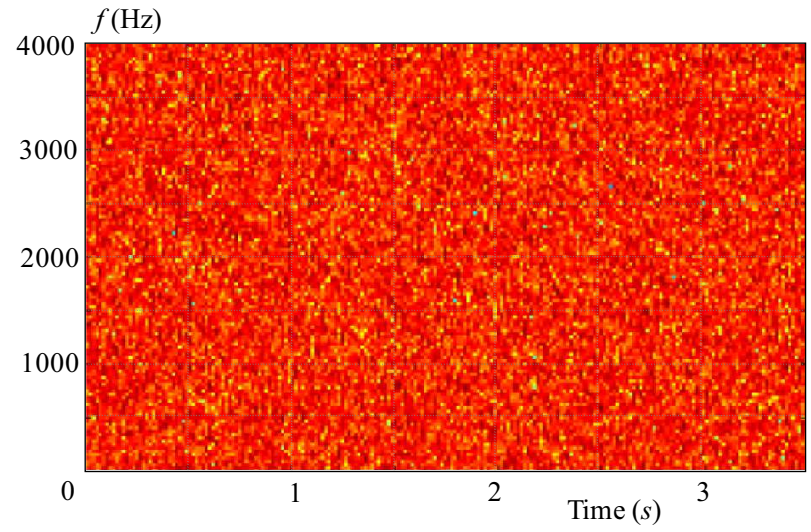

Fig. 16. Noisy speech signal

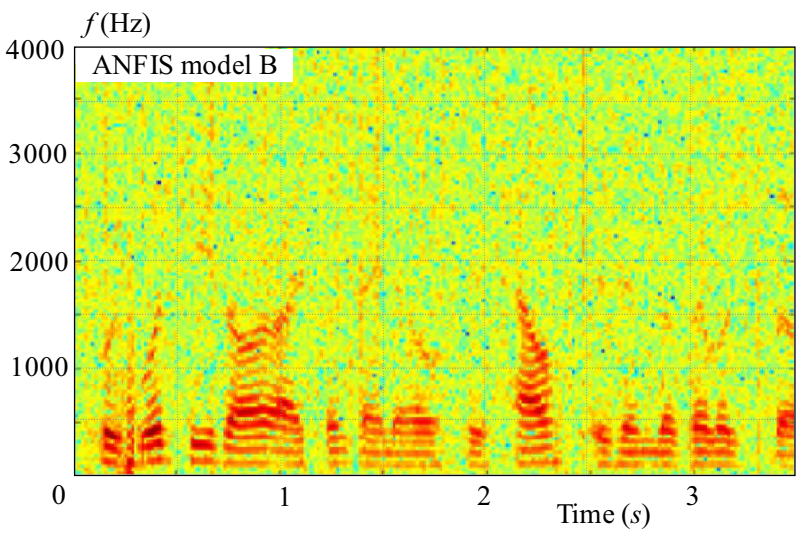

Fig. 18. Results of noise cancellation — ANFIS model B

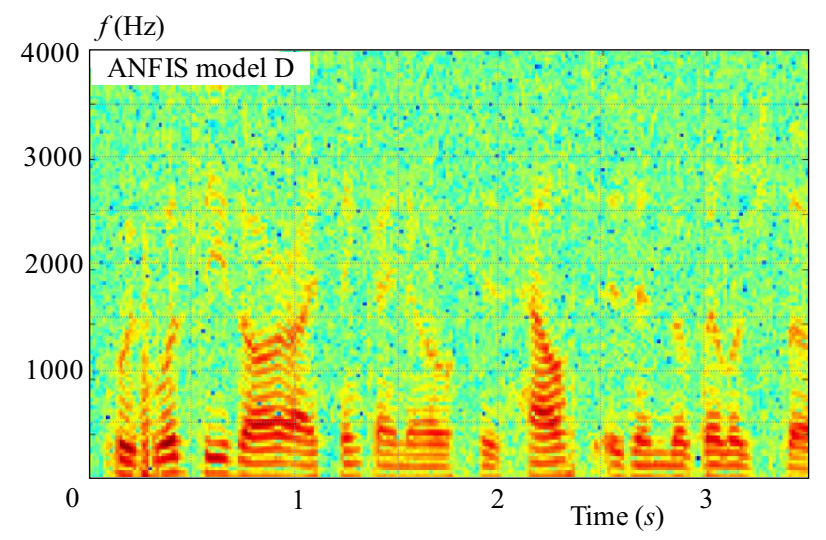

Fig. 20. Results of noise cancellation - ANFIS model C

achieved a significant improvement in the $S S N R$ and $D T W$ values.

Figures 15 to 20 show spectrograms of the analyzed signals. This is a $3 \mathrm{D}$ graph that has two axes with independent variables - frequency and time (order of sections spectra). A $2 \mathrm{D}$ spectrogram is used here; it is a top view of the original 3D graph.

Figures 21 to 23 show 3D spectrograms of the analysed signals. A 3D spectrogram is a kind of a spectrogram that is displayed in a three-dimensional space. Compared to the traditional spectrogram, we put intensity of individual frequencies on axis $z$. If, at a certain time, we make a 


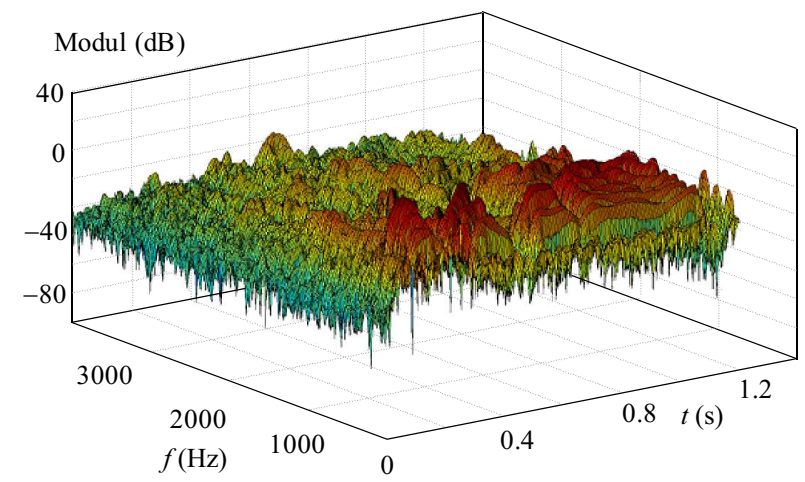

Fig. 21. Original speech signal

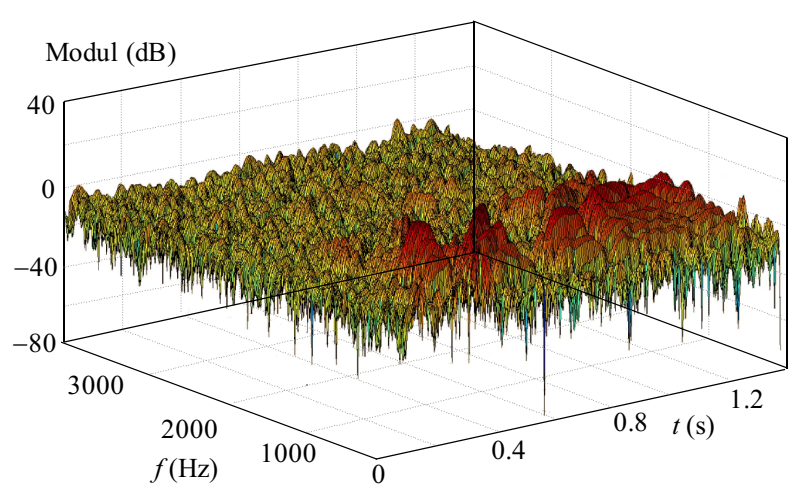

Fig. 23. Results of noise cancellation — ANFIS model B

cross section of the $3 \mathrm{D}$ spectrogram with a plane parallel to the frequency axis and axis $z$, we obtain a spectrum of signals at this time.

\section{DISCUSSION}

Various ANFIS structures were examined during the experiments conducted, see Tab. 1. The experiments conducted confirmed the functionality of the technique designed. The experiments showed that the technique designed can successfully extract the speech signal even if it is completely contaminated by the background noise. The results (SNR, SSNR and DTW) indicate that systems using ANFIS show better experimental results than conventional systems based on adaptive algorithms of the LMS and RLS families [1,2].

As for actual implementation in commercial equipment, ANFIS Model B seems to be the most convenient. This model is a good compromise in terms of mathematical performance (Tab. 1) and results achieved (Tabs. 2 and 3). More complex ANFIS models (C,D) achieve slightly better results, however, at the expense of higher computational demands for the algorithm.

The increase of the SSNR is the most important objective criterion for comparison of the effectiveness of different algorithms; see Tab. 3.

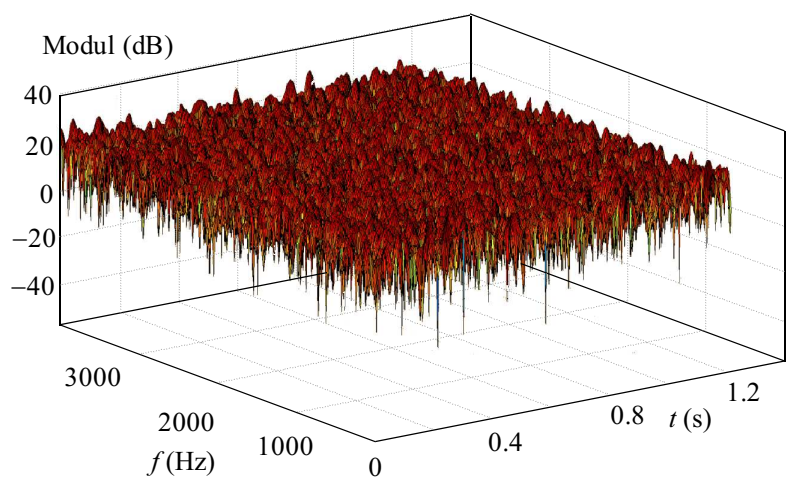

Fig. 22. Noisy speech signal

The authors also conducted listening tests of clarity. Here, ANFIS model A achieved the worst results (worse clarity). Other ANFIS models examined, B, C and D, achieved, from the subjective point of view of the listening tests, the same results.

In practice, the lowest possible costs for implementation of adaptive systems are, of course, required while maintaining a high quality of unwanted noise suppression. From the perspective of production costs, the most convenient solution will be to construct system for ANFIS Model B. In the future, we can expect a steady increase in performance and quality in the area of computer technology. With the advent of more efficient hardware, the requirements for a low computational complexity and memory consumption of the algorithms will be decreased and, therefore, more complex and more efficient algorithms can be implemented. Hence, it is obvious that the area of adaptive filtration still is and will be, for a long time to come, a wide open area for scientific research as well as commercial applications.

\section{CONCLUSION}

An effective noise cancellation in speech was undertaken with the use of adaptive noise cancellation techniques because fixed filters would necessitate the redesign of the filter once the variations exist in the communication channel. The noise which interferes with speech signals in transmission varies depending on the propagation path which is mostly unknown. An adaptive canceller which can automatically adjust itself to the environment is therefore employed.

This article has clearly investigated the use of adaptive neuro-fuzzy inference system (ANFIS) for effective noise suppression in speech. In this paper, adaptive noise cancellation using ANFIS has been implemented on audio speech signal (voice communication). The adaptation algorithm is based on the learning ability of ANFIS. In experiments, we have achieved better performance. This type of adaptive noise cancelling technology can be used when there is a characteristic of an unknown external interference source and the background noise is similar to 
the measured noise. This technology can cancel the external disturbance, and the high signal-to-noise ratio signal is obtained.

ANFIS has two advantages over the LMS and RLS algorithms in low SNR environment. Experiments have been evidently performed on these three distinct approaches and results drawn. A concise analysis and constructive comparison was afterward documented in order to achieve the aim and objectives of the article. One, it is more efficient to eliminate noise. The second, it offers faster convergence time.

The future work includes the optimization of algorithms for all kinds of noises and to use the optimized one in the implementation of FPGA and LabVIEW.

\section{Acknowledgment}

This work is partially supported by the project SGS SP2015/181 VSB - Technical University of Ostrava, Czech Republic.

\section{REFERENCES}

[1] MARTINEK, R.-ZIDEK, J.: Use of Adaptive Filtering for Noise Reduction in Communication systems, In Conference Proceeding: The International Conference Applied Electronics (AE), Pilsen, Czech Republic. 8-9 September 2010, pp. 215-220.

[2] MARTINEK, R.-ZIDEK, J.: A System for Improving the Diagnostic Quality of Fetal Electrocardiogram, Przeglad Elektrotchniczny (Electrical Review) R 88 No. 5b (May 2012), 164-173.

[3] CASTillo, O.-MELiN, P.: Type 2 Fuzzy Logic: Theory and Applications, 2008.

[4] SHUKLA, A.-TIWARI, R.-KALA, R: Towards Hybrid and Adaptive Computing, 1st Edition, 2010.

[5] ROBERTS, M. J: Signals and Systems: Analysis Using Transform Methods and MATLAB, The McGraw-Hill Companies, USA, 2008.

[6] HAYKIN, S: Adaptive Filter Theor. 4th, Prentice Hall, New Jersey, 2001.

[7] BLANCHET, G.-CHARBIT, M: Digital Signal and Image Processing using MATLABß, ISTE USA, Newport Beach, CA 92663, USA, 2006.

[8] WennA, L.-PEIFENG, W.-YANG, L: A Method of Adaptive Colored Noise Cancellation Based on ANFIS, International Conference on Image Analysis and Signal Processing, 2009, IASP 2009, Taizhou, pp. 386-388.

[9] MIRY, M. H.-KHLEAF, H. K: Adaptive Noise Cancellation for Speech Employing Fuzzy and Neural Network, 1-st International Conference on Energy, Power and Control (EPC-IQ), 2010, pp. 289-296.

[10] ITU-T Test Signals for Telecommunication Systems, ITU-T P. 501, http://www.itu.int/en/Pages/default.aspx.

[11] ITU-T Recommendation P.34 was revised by the ITU-T Study Group XII (1988-1993) and was approved by the WTSC (Helsinki, March 1-12, 1993), http://www.itu.int/net/itu-t/sigdb/genaudio..

[12] REYES, J. A. T.-HERNANDEZ, E. E.-GARCIA, J. C. S: DSP-Based Oversampling Adaptive Noise Canceller for Background Noise Reduction for Mobile Phones, International Conference on Electrical Communications and Computers (CONIELECOMP), 2012, MathWorks, Cholula, Puebla, pp. 327-332.

[13] Matlab R2012b - Adaptive Noise Cancellation, Demonstration of Adaptive Nonlinear Noise Cancellation using the Fuzzy Logic
Toolbox ${ }^{\mathrm{TM}}$ Functions ANFIS and GENFIS1, http:// www.mathworks.com/products/fuzzy-logic/examples.html.

[14] MathWorks, Matlab R2012b - Fuzzy Logic Toolbox, http://www.mathworks.com/help/fuzzy/index.html. .

[15] MathWorks, Matlab R2012b - genfis1 and anfis - Generate Fuzzy Inference System structure from Data using Grid Partition, http://www.mathworks.com/help/fuzzy/genfis1.html..

16] KURIAN, C. P.et al : ANFIS Model for the Time Series Prediction of Interior Daylight Illuminance, International Journal on Artificial Intelligence and Machine Learning No. 6.3 (2006), $35-40$.

[17] JANG, J.-S. R : Fuzzy Modeling Using Generalized Neural Networks and Kalman Filter Algorithm, Proc. of the Ninth National Conf. on Artificial Intelligence (AAAI-91), July 1991, pp. $762-767$.

[18] JANG, J.-S. R. ANFIS: Adaptive-Network-based Fuzzy Inference Systems : IEEE Transactions on Systems, Man, and $\mathrm{Cy}-$ bernetics 23 No. 3 (May 1993), 665-685.

[19] VASEGHI, S. V.: Advanced Digital Signal Processing and Noise Reduction, 4 edition, John Wiley \& Sons Inc (E), 2008.

[20] STAVROULAKIS, P (editor): Neuro-Fuzzy and Fuzzy-Neural Applications in Telecommunications (Signals and Communication Technology), Springer (24 Mar 2004).

[21] ZAFAR, Z.-JAVED, A.-ZAID, S: Autopilot System for an Unmanned Aerial Vehicle (UAV): Adaptive Neuro Fuzzy Inference Based Control System.LAP, Lambert Academic Publishing (10 Mar 2011)

22] PATEL, J.-GIANCHANDANI, R: ANFIS Control for Robotic Manipulators: Adaptive Neuro Fuzzy Inference Systems for Intelligent Control, LAP Lambert Academic Publishing (25 Nov 2011).

[23] KONDOZ, A. M: Digital Speech: Coding for Low Bit Rate Communication Systems, 2nd Edition (24 Sep 2004), Wiley-Blackwell.

[24] HIRSH, H. G.-FINSTER, H.: The Simulation of Realistic Acoustic Input Scenarios for Speech Recognition Systems, Interspeech conference, Lisbon, Portugal, 2005, pp. 2697-2700.

[25] MAKINO, S.-KANEDA, Y.-KOIYUMI, N.: Exponentially Weighted Step-Size NLMS Adaptive Filter Based on the Statistics of a Room Impulse Response, IEEE Trans. Speech and Audio Processing 1 No. 1 (1993), 101-108.

[26] SILZLE, A.-NOVO, P.-STRAUSS, H. : IKA-SIM: A System to Generate Auditory Virtual Environments, 116th Convention of the Audio Engineering Society, Berlin, Germany, 2004.

[27] PROAKIS, J. G.-MANOLAKIS, D. K. : Digital Signal Processing: Principles, Algorithms, and Applications, 4 edition (15 Feb 2006), Pearson.

28] MARTINEK, R.-ZIDEK, J.: Refining the Diagnostic Quality of the Abdominal Fetal Electrocardiogram using the Techniques of Artificial Intelligence, Przeglad Elektrotchniczny (Electrical Review) 88 No. 12b (2012), 155-160.

[29] MARTINEK, R.-ZIDEK, J.: The Real Implementation of NLMS Channel Equalizer into the System of Software Defined Radio, Advances in Electrical and Electronic Engineering 10 No. 5 (Dec 2012), 330-336.

[30] VANUS, J.-STYSKALA, V.: Application of Variations of the LMS Adaptive Filter for Voice Communications with Control System, Tehnicki Vjesnik 18 (2011), 555-580.

[31] VANUS, J.: The Use of the Adaptive Noise Cancellation for Voice Communication with the Control System, International Journal of Computer Science and Applications 8 (2011), 54-70.

[32] MARTINEK, R.-KELNAR, M.-KOUDELKA, P.—VANUS, J.-BILIK, P.-JANKU, P.-NAZERAN, H.-ZIDEK, J. : Enhanced Processing and Analysis of Multi-Channel Non-Invasive Abdominal Foetal ECG Signals during Labor and Delivery, Electronics Letters 51 No. 22 (Oct 2015), 1738-1740. 
[33] MARTINEK, R.-KELNAR, M.-VANUS, J.-KOUDELKA, P.-BILIK, P.-KOZIOREK, J.-ZIDEK, J. : Adaptive Noise Suppression in Voice Communication Using a Neuro-Fuzzy Inference System, In 38th International Conference on Telecommunications and Signal Processing (TSP), Prague, Czech Republic, 9-11 July 2015, pp. 382-386.

[34] MARTINEK, R.-VANUS, J.-KELNAR, M.-BILIK, P. : Control Methods of Active Power Filters Using Soft Computing Techniques., In 8th International Scientific Symposium on Electrical Power Engineering (Elektroenergetika), Stara Lesna, Slovakia, 16-18 September 2015, pp. 363-366.

[35] MARTineK, R.-VANUS, J.-BILIK, P.: New Strategies for Application of Recursive Least Square Algorithm in Active Power Filters, In 8th International Scientific Symposium on Electrical Power Engineering (Elektroenergetika), Stara Lesna, Slovakia, 16-18 September 2015, pp. 344-347.

[36] MARTINEK, R.-ZIDEK, J.: The Real Implementation of ANFIS Channel Equalizer on the System of Software-Defined Radio, IETE Journal of Research 60 No. 2 (2014), 183-193.

[37] MARTINEK, R.-MANAS, J.-ZIDEK, J.-BILIK, P.: Power Quality Improvement by Shunt Active Performance Filters Emulated by Artificial Intelligence Techniques, 2nd International Conference on Advances in Computer Science and Engineering (CSE 2013), Los Angeles, CA, USA, 1-2 July 2013, pp. 157-161.

[38] MARTINEK, R.-KELNAR, M.-VOJCINAK, P.-KOUDELKA, P.-VANUS, J.-BILIK, P.-JANKU, P.-NAZERAN, H.-ZIDEK, J. : Virtual Simulator for the Generation of Patho-Physiological Foetal ECGs during the Prenatal Period, Electronics Letters 51 No. 22 (Oct 2015), 1744-1746.

[39] MULLER, M.: Dynamic Time Warping, Information Retrieval for Music and Motion (2007), 69-84.

Received 1 December 2014

Radek Martinek was born on 10 August 1984 in Nove Mesto na Morave, Czech Republic. He received his Master's degree in Information and Communications Technology from VSB-TU of Ostrava in 2009. In 2014, he successfully defended his dissertation thesis on "The use of complex adaptive methods of signal processing for refining the diagnostic quality of the abdominal fetal electrocardiogram". Since 2014 he has worked at the VSB-TU Ostrava (Technical University) as an assistant professor. His current research interests include Digital Signal Processing (Adaptive Filtering, Adaptive Neuro-Fuzzy Inference Systems), Biological Signal Processing (Fetal ECG), Modern Communication Technology (SoftwareDefined Radio, Wireless Channel Equalization, and Optical
Wireless Communication) and Graphical Programming (Virtual Instruments).

Michal Kelnar was born in 1988 in Novy Jicin, Czech Republic. He received his master's degree in Measurement and Control Engineering at the Technical University of Ostrava in 2013. Since 2013, he is working on a dissertation thesis based on progressive methods of data processing in embedded systems. His main interests are text-based and also graphical programming, signal processing and design of distributed measurement-control systems.

Jan Vanus was born in 1972 in Rymarov. He completed studies at the Faculty of Electronics and Computer Science at the Technical University of Ostrava in the field of Measuring and Control Technologies in 1996. Since 2001 he has worked at the VŠB -TU Ostrava (Technical University) as an assistant professor. In 2010, he successfully defended his dissertation thesis on "Voice communication with control system." Since 2012, he has been working at the Department of Cybernetics and Biomedical Engineering at the Technical University of Ostrava within the Postdoc Grant called an opportunity for young researchers. At present, the author focuses on the design and implementation of operational and technical management functions in Smart Home and in Smart Home Care.

Petr Bilik was born in 1968. He received his Master degree in Power Electronics from VSB Technical University in 1991, he finished his PhD study in the field of Technical Cybernetics in 2004. From 2000 until 2012 he worked as the head of Power Quality Measurement System department in commercial company. Currently he is vice-head of Department of Cybernetics and Biomedical Engineering. His main interests are automated test and measurement systems design, data acquisition, graphical programming.

Jan Zidek was born in 1957 in Opava, Czech Republic. He received his Master's degree in Power Engineering from VSB-TU of Ostrava in 1982, finished his PhD study in 1986. From 1991 until 2003 he worked as the head of Department of Electrical Measurement, which was established at the new Faculty of Electrical Engineering and Computer Science on VSB-TU of Ostrava. He works as the vice-dean of this faculty from 2003 and is a member of the Department of Cybernetics and Biomedical Engineering. His main interests are graphical programming, automated test, and measurement systems design, measurement in communication systems, power quality measurement. 